
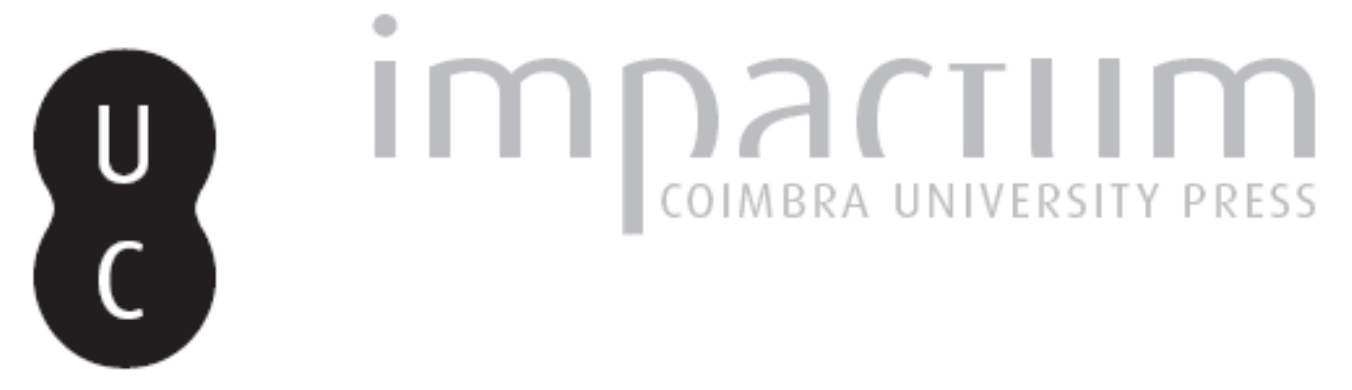

\title{
A educação nas constituições brasileiras
}

\author{
Autor(es): Bulhões, Raquel Recker Rabello
}

Publicado por: Universidade Católica de Petrópolis

URL persistente:

URI:http://hdl.handle.net/10316.2/33904

DOI:

DOI:http://dx.doi.org/10.14195/2175-0947_1-1_6

Accessed : $\quad$ 26-Apr-2023 00:11:20

A navegação consulta e descarregamento dos títulos inseridos nas Bibliotecas Digitais UC Digitalis, UC Pombalina e UC Impactum, pressupõem a aceitação plena e sem reservas dos Termos e Condições de Uso destas Bibliotecas Digitais, disponíveis em https://digitalis.uc.pt/pt-pt/termos.

Conforme exposto nos referidos Termos e Condições de Uso, o descarregamento de títulos de acesso restrito requer uma licença válida de autorização devendo o utilizador aceder ao(s) documento(s) a partir de um endereço de IP da instituição detentora da supramencionada licença.

Ao utilizador é apenas permitido o descarregamento para uso pessoal, pelo que o emprego do(s) título(s) descarregado(s) para outro fim, designadamente comercial, carece de autorização do respetivo autor ou editor da obra.

Na medida em que todas as obras da UC Digitalis se encontram protegidas pelo Código do Direito de Autor e Direitos Conexos e demais legislação aplicável, toda a cópia, parcial ou total, deste documento, nos casos em que é legalmente admitida, deverá conter ou fazer-se acompanhar por este aviso.

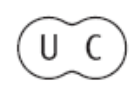



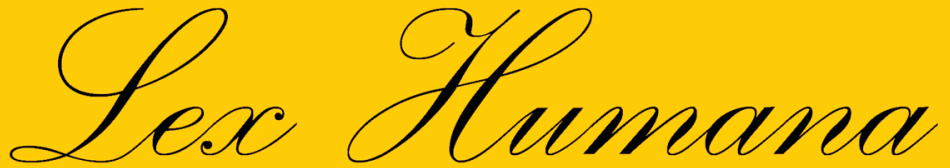

Revista do Programa de Pós-Graduação em Direito da UCP

ISSN(e) 2175-0947

Universidade Católica de Petrópolis Rua Benjamin Constant, 213 - Petrópolis - Centro CEP 25610-130

Tel: (24) 2244-4000 E-mail: lexhumana@ucp.br 


\title{
A EDUCAÇÃO NAS CONSTITUIÇÕES BRASILEIRAS
}

\author{
Raquel Recker Rabello Bulhões
}

\section{Introdução}

A criança e o adolescente nem sempre tiveram voz e vez, seja na família, na escola, na comunidade ou na sociedade, quanto mais na legislação. Esta situação foi se modificando a partir de meados do século XX, quando estudiosos tiveram como foco central de suas pesquisas investigá-los como sujeitos do meio social. Até então, os estudos relativos à infância, ou que envolvessem questões pertinentes à criança ou ao adolescente, partiam do pressuposto de que eles eram apenas objetos de estudo, e, desta forma, não se levava em consideração que pudessem ter códigos, linguagens, pensamentos, sentimentos e expectativas individuais. As crianças e os adolescentes eram estudados sob o prisma dos adultos, e, portanto, eram tidas como "adultos em miniatura", meros receptáculos do que lhes era depositado em linguagem, cultura e educação.

Os estudos atuais demonstram que as crianças também são criadoras da cultura e, portanto, sujeitos da sua história e co-partícipes da sociedade. Por isso, captar a perspectiva da criança e traçar meios para que seus anseios sejam observados é uma realidade em quase todas as culturas e legislações. É sob esta vertente, que passa a considerar as crianças e adolescentes como sujeitos de direitos, que este artigo é realizado, buscando-se compreender como esses atores interagem no cenário social em nosso país. Os novos protagonistas adquiriram o "status" de cidadãos por meio de alguns segmentos da sociedade, que, conscientes do seu papel, intercederam por elas e lutaram para que seus direitos fossem tutelados no texto constitucional brasileiro, respeitados e resguardados, e que fossem punidos aqueles que os violassem. Desta forma, a partir do final dos anos oitenta, quando da entrada em vigor da atual Constituição Federal, as crianças e os adolescentes adquiriam a tão sonhada cidadania. 


\section{A educação nas Constituições Brasileiras}

A preocupação do Poder Público, no que se refere à educação, encontra-se presente em todas constituições brasileiras: desde a primeira delas, pós-independência, outorgada por D. Pedro I, em 1824; passando pela Republicana de 1891; a do Estado Novo de 1934; a de 1937; a de 1946, quando da redemocratização do país; seguida pela de 1967, de inspiração militar com limitação do poder da sociedade civil na escolha de seus governantes; com a agravante do AI-5 de 1968, que desencadeou a Emenda Constitucional n 1 de 1969, até chegarmos à Constituição de 1988, oitava constituição brasileira, denominada pelo seu principal artífice, o deputado Ulysses Guimarães, de "Constituição cidadã”. Apesar disso, observar-se que o enfoque dado à educação nas constituições brasileiras nem sempre foi $o$ mesmo, sofrendo consideráveis modificações com o decurso do tempo.

A Constituição do Império de 1824, que foi outorgada por D. Pedro I sem que houvesse qualquer participação da nação, não se preocupou em dedicar um capítulo específico para a educação, referindo-se a ela em apenas dois incisos ${ }^{1}$ do art. 179. No que se refere aos interesses da criança e do adolescente, nota-se que o inciso XXXII deste artigo disciplinava a respeito da gratuidade da instrução primária para todos os cidadãos. No entanto, vale lembrar que os direitos e garantias elencados nesta Carta tinham por objetivo atender às reivindicações liberais de Portugal e, sendo assim, a gratuidade universal à educação primária inseriu-se no texto como uma obrigação efetiva do Estado e não foi fruto de interesses articulados e reclamos sociais organizados.

Logo após a Proclamação da República, em 15 de novembro de 1889, foi criada a primeira Constituição Republicana do Brasil, de 1891, elaborada por Rui Barbosa, na qual, ao contrário da Carta anterior, houve a participação dos representantes do povo brasileiro, que reunidos em Congresso Constituinte, com o objetivo de organizar um regime livre e democrático, estabeleceram, decretaram e promulgaram a primeira Constituição Republicana. Esta Constituição traz uma abordagem indireta da

1 Art. 179 CI/24 - A inviolabilidade dos Direitos Civis, e Politicos dos Cidadãos Brazileiros, que tem por base a liberdade, a segurança individual, e a propriedade, é garantida pela Constituição do Imperio, pela maneira seguinte: XXXII. A Instrucção primaria, e gratuita a todos os Cidadãos.

XXXIII. Collegios, e Universidades, aonde serão ensinados os elementos das Sciencias, Bellas Letras, e Artes. 
educação, prevista no Título IV, referente aos Cidadãos Brasileiros, e inserida na Seção II, que dispõe sobre as Declarações de Direitos. Na leitura do art. $72 \S 6^{\circ}$ desta Carta $^{2}$, nota-se que os constituintes mantiveram o princípio da liberdade e da laicidade do ensino ministrado nos estabelecimentos públicos, mas silenciaram a respeito da sua gratuidade. Verifica-se, também, que esta Constituição consagra a separação do Estado e da Igreja, limitando, deste modo, os poderes de ingerência de um sobre o outro.

Sob o influxo da Revolução de 30, a Constituição da República dos Estados Unidos do Brasil, promulgada em 16 de julho de 1934, representou um processo de modernização do Estado, assegurando, pela primeira vez na história, a educação como um direito de todos, devendo ser ministrada pela família e pelos poderes públicos. Ela mantém a gratuidade do ensino primário e propõe sua extensão a outros níveis de ensino. Segundo Fávero (2005, p. 13), o texto constitucional de 1934 deixa antever que o direito à educação passa a ser "condividido" entre o Estado e a família. Nesta Carta o direito à educação ${ }^{3}$ aparece disposto, de forma explícita, no art. 149, que compreende as disposições acerca da família, da educação e da cultura.

A partir desta Carta houve a inclusão da família, como um lugar de educação, que será visível em todas as constituições posteriores. Nesse sentido, a família tem a obrigatoriedade de enviar e manter os filhos nas escolas, enquanto incumbe aos poderes públicos assegurar a gratuidade do ensino. Sendo assim, a União deveria se responsabilizar pela tarefa progressiva de fundar e manter escolas secundárias e superiores gratuitas, conforme se verifica no art. 150 parágrafo único ${ }^{4}$, alíneas a, b e c.

2 Art 72 CR/91- A Constituição assegura a brasileiros e a estrangeiros residentes no País a inviolabilidade dos direitos concernentes à liberdade, à segurança individual e à propriedade, nos termos seguintes:

$\S 6^{\circ}$ - Será leigo o ensino ministrado nos estabelecimentos públicos.

3 Art 149 CREUB/34 - A educação é direito de todos e deve ser ministrada, pela família e pelos Poderes Públicos, cumprindo a estes proporcioná-la a brasileiros e a estrangeiros domiciliados no País, de modo que possibilite eficientes fatores da vida moral e econômica da Nação, e desenvolva num espírito brasileiro a consciência da solidariedade humana.

4 Parágrafo único - O plano nacional de educação constante de lei federal, nos termos dos arts. $5^{\circ}, \mathrm{n}^{\circ} \mathrm{XIV}$, e $39, \mathrm{n}^{\circ} 8$, letras $a$ e $e$, só se poderá renovar em prazos determinados, e obedecerá às seguintes normas: a) ensino primário integral gratuito e de freqüência obrigatória extensivo aos adultos; b) tendência à gratuidade do ensino educativo ulterior ao primário, a fim de o tornar mais acessível; c) liberdade de ensino em todos os graus e ramos, observadas as 
A Constituição de 1937 foi a segunda Carta brasileira outorgada, neste caso, pelo Estado Novo, em decorrência das condições políticas e ideológicas, tanto internas quanto externas, que terminaram por derrubar o renovador texto constitucional. Seu prefácio deixa claro que não houve uma participação do povo ao se decretar esta Constituição, que teve por objetivo "assegurar à Nação a sua unidade, o respeito à sua honra e à sua independência, e ao povo brasileiro, sob um regime de paz política e social, as condições necessárias à sua segurança, ao seu bem-estar e à sua prosperidade", determinando, ainda, o seu cumprimento obrigatório em todo o País. Esta Carta significou um retrocesso considerável em relação à Constituição anterior, especialmente no item que se refere à educação, atribuindo-se à família a responsabilidade primeira pela educação integral da prole, e ao Estado o dever de colaborar para a execução dessa responsabilidade. Observa-se que o art. 130 define o ensino primário como obrigatório e gratuito ${ }^{5}$, mas, a ênfase do texto referese à subsidariedade do Estado no provimento da educação àqueles a quem faltarem recursos.

A partir da Constituição Federal de 1946 é a sociedade, e não o Estado, quem tem a primazia. A liberdade tinha por objetivo permitir uma maior participação popular na vida social e econômica. Nesta Carta a educação passa a ser vista como um direito público subjetivo; no entanto, sabe-se que à família também incumbe o dever de educar os filhos. Nesse sentido, pode-se afirmar que a educação baseia-se no princípio "in loco parentis", devendo ser ministrada tanto no lar quanto na escola. No que se refere especificamente ao direito à educação ${ }^{6}$ (art. 166), as idéias contidas nesta Constituição assemelham-se às da Carta de 1934. Sendo assim, a educação encontra-se prevista no capítulo II, que dispõe sobre a Educação e a Cultura. Os incisos I e II do art. 168, definem a obrigatoriedade e a gratuidade ao ensino primário oficial $^{7}$, no entanto, a ênfase do texto refere-se à subsidariedade do Estado

prescrições da legislação federal e da estadual;

$5 \quad$ Art $130 \mathrm{CEUB}^{\mathrm{a}} / 37$ - O ensino primário é obrigatório e gratuito. A gratuidade, porém, não exclui o dever de solidariedade dos menos para com os mais necessitados; assim, por ocasião da matrícula, será exigida aos que não alegarem, ou notoriamente não puderem alegar escassez de recursos, uma contribuição módica e mensal para a caixa escolar.

6 Art 166 CEUB $^{\mathrm{b}} / 46$ - A educação é direito de todos e será dada no lar e na escola. Deve inspirar-se nos princípios de liberdade e nos ideais de solidariedade humana. 
no provimento do ensino oficial posterior para aqueles que provarem a falta ou insuficiência de recursos.

Vale lembrar que um dos desdobramentos trazidos pela Constituição neoliberal de 1946 diz respeito ao ciclo das leis de diretrizes e bases, sendo a Lei $n^{\circ} 4.024 / 61$ (Lei de Diretrizes e Bases - $\operatorname{LDBEN}^{1}$ ) a primeira lei geral de educação. Esta Lei previa o Plano Nacional de Educação (PNE), que foi elaborado em 1962, revisto em 1965 e complementado pelo Conselho Federal de Educação (CFE) em 1966. O PNE visava instrumentalizar os dois princípios fundamentais da $\operatorname{LDBEN}^{1}$, ou seja, o direito de todos à educação e a igualdade de oportunidades.

A Constituição de 1967, de inspiração militar, com limitação do poder da sociedade civil na escolha de seus governantes, foi decretada e promulgada pelo Congresso Nacional. O direito à educação encontra-se previsto no art. 168, quando trata da Família, da Educação e da Cultura ${ }^{8}$. O texto constitucional mantém alguns princípios gerais da educação, como o direito de todos, a liberdade de ensino, a igualdade de oportunidades e a limitação da gratuidade, mas inaugura o regime de bolsas de estudos restituíveis, no ensino superior.

A Emenda Constitucional no 1 de 1969 representou, na realidade, uma

princípios:

I - o ensino primário é obrigatório e só será dado na língua nacional; II - o ensino primário oficial é gratuito para todos; o ensino oficial ulterior ao primário sê-lo-á para quantos provarem falta ou insuficiência de recursos; 8 Art 168 CRFB/67 - A educação é direito de todos e será dada no lar e na escola; assegurada a igualdade de oportunidade, deve inspirar-se no princípio da unidade nacional e nos ideais de liberdade e de solidariedade humana.

$\S 1^{\circ}$ - O ensino será ministrado nos diferentes graus pelos Poderes Públicos.

$\S 2^{\circ}$ - Respeitadas as disposições legais, o ensino é livre à iniciativa particular, a qual merecerá o amparo técnico e financeiro dos Poderes Públicos, inclusive bolsas de estudo.

$\S 3^{\circ}$ - A legislação do ensino adotará os seguintes princípios e normas:

I - o ensino primário somente será ministrado na língua nacional;

II - o ensino dos sete aos quatorze anos é obrigatório para todos e gratuito nos estabelecimentos primários oficiais;

III - o ensino oficial ulterior ao primário será, igualmente, gratuito para quantos, demonstrando efetivo aproveitamento, provarem falta ou insuficiência de recursos. Sempre que possível, o Poder Público substituirá o regime de gratuidade pelo de concessão de bolsas de estudo, exigido o posterior reembolso no caso de ensino de grau superior; 
nova Constituição, com características mais ditatoriais que sua antecessora. Foi responsável pelo esvaziamento dos princípios e mecanismos assegurados nas Cartas de 1934 e 1946. No entanto, manteve todos os dispositivos referentes à educação e reconheceu, pela primeira vez (art. 176), que a educação é um direito de todos e dever do Estado ${ }^{9}$, devendo ser ministrada tanto no lar quanto na escola. As bolsas de estudos restituíveis se estendem ao ensino médio.

A proposta da Constituinte atual mobilizou a sociedade brasileira, sendo a educação um dos temas mais discutidos. Os debates que antecederam a promulgação da Carta de 1988 foram marcados pela produção de estudos que analisaram a educação nos textos constitucionais, mas principalmente pelo confronto entre os que defendiam a ensino público, laico e gratuito em todos os níveis, em oposição ao setor privado, interessado em obter acesso às verbas públicas. A Constituinte de 1987-88 incorporou a participação da sociedade civil organizada através de consulta a entidades coletivas representativas. Entre as articulações do ensino público e privado destacaram-se o Fórum de Educação na Constituinte em Defesa do Ensino Público e Gratuito, os encontros da Federação Nacional dos Estabelecimentos de Ensino (FENEN) e das Escolas Confessionais.

Em 05 de outubro de 1988, após 20 anos de regime autoritário, foi promulgada uma nova Constituição em clima de democracia, já que era a nação quem legitimava suas normas através de um processo constituinte, por

9 Art 176 EC/69- A educação, inspirada no princípio da unidade nacional e nos ideais de liberdade e solidariedade humana, é direito de todos e dever do Estado, e será dada no lar e na escola.

$\S 1^{\circ}$ - O ensino será ministrado nos diferentes graus pelos Poderes Públicos. $\S 2^{\circ}$ - Respeitadas as disposições legais, o ensino é livre à Iniciativa particular, a qual merecerá o amparo técnico e financeiro dos Poderes Públicos, inclusive bolsas de estudo.

$\S 3^{\circ}$ - A legislação do ensino adotará os seguintes princípios e normas:

I - o ensino primário somente será ministrado na língua nacional;

II - o ensino primário é obrigatório para todos dos sete aos quatorze anos é gratuito nos estabelecimentos primários oficiais;

III - o ensino público será igualmente gratuito para quantos, no nível médio e superior, demonstrarem efetivo aproveitamento e provarem falta ou insuficiência de recursos.

IV - O Poder Público substituirá, gradativamente, o regime de gratuidade no ensino médio e no superior pelo sistema de concessão de bolsas de estudo, mediante restituição, que a lei regulará; 
isso, ficou ela ficou conhecida como "Constituição Cidadã". Nesta Carta, o direito à educação ${ }^{10}$ foi considerado um direito social e aparece previsto no art 205, que trata da Educação, da Cultura e do Desporto.

Oliveira (2001, p. 15-43), ao discutir historicamente a concepção do direito à educação contida nos textos legais das constituições brasileiras, concentra-se na Constituição Federal de 1988, em especial nos artigos 208 e 227. O autor ressalta a importância da criação da Lei no 8.069/90 (ECA), cuja finalidade primordial é a de zelar pelo cumprimento dos direitos da criança e do adolescente previstos na legislação em vigor. Não é demais lembrar que o preceito constitucional do artigo 227 determina a obrigatoriedade da família, da sociedade e do Estado em assegurar à criança e ao adolescente, com absoluta prioridade, entre outros, o direito à educação.

Sabe-se que atualmente a família passa por mudanças, e, por isso, a escola torna-se o espaço basilar que proporcione às crianças e aos adolescentes, cujas famílias enfrentam dificuldades, tanto de cunho emocional quanto material, um ambiente favorável ao desenvolvimento saudável, onde seja possível construir valores e ética. A escola torna-se a saída que estas crianças e adolescentes possuem para desenvolver sua capacidade de pensar, sonhar e buscar modelos saudáveis. Nesse sentido, Aragão e Vargas (2005, p. 72), defendem que "a letra da lei deve ceder lugar à efetivação de práticas assecuratórias ao direito da criança e do adolescente de ter acesso à educação, à cultura, ao esporte e ao lazer".

Partindo-se da premissa de que a educação é essencial para o desenvolvimento humano integral, torna-se necessário garantir a igualdade de condições de acesso e permanência na escola, de forma que esse direito não seja mitigado em virtude de políticas públicas ineficazes ou insuficientes.

Conforme dispõe o art. 195 caput da Carta Magna ${ }^{11}$ de 1988, as ações governamentais educacionais, por se tratar da área da assistência social, serão financiadas por toda sociedade e realizadas com recursos provenientes do orçamento da seguridade social. No entanto, com o propósito de resguardar

10 Art 205 - A educação, direito de todos e dever do Estado e da família, será promovida e incentivada com colaboração da sociedade, visando ao pleno desenvolvimento da pessoa, seu preparo para o exercício da cidadania e sua qualificação para o trabalho.

11 Art. 195 - A seguridade social será financiada por toda a sociedade, de forma direta e indireta, nos termos da lei, mediante recursos provenientes dos orçamentos da União, dos Estados, do Distrito Federal e dos Municípios, e das seguintes contribuições sociais: (...) 
o seu efetivo cumprimento, a lei prevê a possibilidade de que esses recursos possam advir de outras fontes, incluindo a participação da população por meio de organizações representativas na formulação das políticas públicas e no seu controle (art. 204, incisos I e II da Constituição Federal) ${ }^{12}$.

\section{Considerações Finais}

Os artigos referentes à educação, elencados em cada um das Constituições analisadas, refletem os momentos históricos e políticos em que foram concebidas.

Da análise das Cartas Magnas brasileiras, de 1824 até 1988, pode-se observar que o Estado vai se tornando cada vez mais presente na seara da educação.

Nota-se que desde os primórdios da nossa história sempre foi dado um grande enfoque nas legislações como forma de assegurar que os direitos fossem respeitados, possibilitando a todos um pleno exercício da cidadania, considerado como tal o direito de viver de forma digna, com a satisfação das necessidades básicas.

No entanto, apesar de todo o esforço das nossas Constituições em salvaguardar a questão da educação, ela ainda está longe dos seus objetivos.

Podemos concluir que não basta garantir esses direitos, torna-se mister, além de protegê-los, efetivá-los, e neste sentido, ainda temos um longo caminho a trilhar.

\section{Refeências Bibliográficas}

ARAGÃO, Selma Regina e VARGAS, Ângelo. O Estatuto da criança e do adolescente em face do novo Código Civil - Cenários da infância e da Juventude brasileira - Rio de Janeiro: Forense, 2005.

12 Art. 204 - As ações governamentais na área da assistência social serão realizadas com recursos do orçamento da seguridade social, previstos no art. 195, além de outras fontes, e organizados com base nas seguintes diretrizes I - Descentralização político-administrativa, cabendo a coordenação e às normas gerais à esfera federal e a coordenação e a execução dos respectivos programas às esferas estadual e municipal, bem como a entidades beneficentes e de assistência social;

II - Participação da população, por meio de organizações representativas, na formulação das políticas e no controle das ações m todos os níveis. 
BRASIL. Constituição (1988). Constituição da República Federativa do Brasil. Brasília, DF: Senado, 1988. Acesso em 23/07/2006 Disponível em: http://www.presidencia.gov.br/legislacao/constituicao/

BRASIL Emenda Constitucional $n^{\circ} 1$ de 1969. Acesso em 23/07/2006 Disponível em: http://www.presidencia.gov.br/legislacao/constituicao/

BRASIL. Constituição (1967). Constituição da República Federativa do Brasil. Disponível em: http://www.presidencia.gov.br/legislacao constituicao-Acesso em 23/07/2006

BRASIL. Constituição (1946). Constituição dos Estados Unidos do Brasil. Disponível em: http://www.presidencia.gov.br/legislacao/constituicao Acesso em 23/07/2006

BRASIL. Constituição (1937). Constituição dos Estados Unidos do Brasil. Disponível em: http://www.presidencia.gov.br/legislacao/constituicao Acesso em 23/07/2006

BRASIL. Constituição (1934). Constituição da República dos Estados Unidos do Brasil. Disponível em: http://www.presidencia.gov.br/legislacao constituicao-Acesso em 23/07/2006

BRASIL. Constituição (1891). Constituição da República dos Estados Unidos do Brasil. Disponível em: http://www.presidencia.gov.br/legislacao constituicao-Acesso em 23/07/2006

BRASIL. Constituição (1824). Constituição Política do Império do Brasil. Disponível em: http://www.presidencia.gov.br/legislacao/constituicao Acesso em 23/07/2006

FAVERO, Osmar (0rg.). A educação nas constituintes brasileiras 1823-1988. $3^{\text {a }}$ ed. - Campinas, SP : Autores Associads, 2005.

LEI No 9.394/96 - Lei n ${ }^{\circ}$ 9.394, de 20 de dezembro de 1996 (DOU 23.12.96) Estabelece as diretrizes e bases da educação nacional. Acesso em 26/11/2006 Disponível em: http://legislacao.planalto.gov.br 
OLIVEIRA, Romualdo Portela de. O direito à educação. In: OLIVEIRA Romualdo Portela de, ADRIÃO, Thereza (Org.). Gestão, financiamento e direito à educação: análise da LDB e da Constituição Federal. São Paulo: Xamã, 2001. 